British Journal of Psychiatry (1993), 163, 547-557

\title{
Correspondence
}

Editor: Ian Pullen

Contents: Dangerous behaviour preceding first admissions for schizophrenia/d-Fenfluramine and cognitive therapy in bulimia nervosa/Diagnostic agreement in psychiatry/Sporadic Pick's disease/ Importance of stratification by age/Long-term antidepressant treatment in the elderly/Patient's perception of family emotional climate/Down's syndrome, dementia, and superoxide dismutase/Home-based acute psychiatric services/Small babies and schizophrenia/A social atmosphere which tolerates eccentrics/Depression of old age/Ageing as a risk factor for lithium neurotoxicity at therapeutic serum levels/ Higher risk groups and paracetamol overdose/ Double firing of ECT machine.

\section{Dangerous behaviour preceding first admissions for schizophrenia}

SIR: In their otherwise meticulous study the authors (Humphreys et al, Journal, October 1992, 161, 501505) do not tell us whether and how they took steps to ascertain whether alcohol or drugs were playing a part in causing dangerous behaviour, and I think they should be invited to do so now.

The most common causes by far of violent behaviour are alcohol and drugs, whether or not the individual is suffering from mental illness and, furthermore, these substances produce symptoms which are commonly misdiagnosed as schizophrenia.

The authors say that they are surprised at the high proportion of schizophrenic patients who acted dangerously. I share their surprise. Similarly, I have referred to their original study (Johnstone et al, Journal, February 1986, 148, 115-120) and have found that of 462 patients referred to their study, only seven were excluded because of drug or alcohol abuse, and although I appreciate that these patients were referred by other psychiatrists, I am equally surprised at this small number. The authors may wish to comment on this point.

Many people, schizophrenic or not, have a propensity for violence; the question is why it appears at a particular time and in a particular person.

\section{Linnell Drive}

SAMuel I. Cohen

London NW11 7LT
AUTHORS' REPLY: We are grateful to Professor Cohen for his interest in this work, and in particular his comments on the role of alcohol and drugs as common contributory factors in mediating violent behaviour.

As Professor Cohen points out, patients included in the original study were referred by psychiatrists, from nine centres, who were asked specifically to exclude any case where alcohol or drugs might have contributed in any way to the primary presentation. The small number of patients subsequently excluded following referral reflects this, as well as the relatively low occurrence of alcohol- and drug-related problems in some areas from which the sample was drawn.

With regard to the role of alcohol or drugs in the individual cases and incidents described, despite the availability of detailed notes of the circumstances of most of the episodes of dangerous behaviour, many took place over an extended period of time, and there were no incidents where intoxication with drugs or alcohol was specifically mentioned. Nonetheless, it is certainly possible that alcohol or drugs did play a part in some of the large number of incidents which took place, on the basis that ingestion of these substances is so frequently implicated when violence occurs, although it is not necessarily a primary cause of what is obviously a multifactorial process.

MARTIN HUMPHREYS

EVE C. JOHNSTONE

\section{The University of Edinburgh \\ Royal Edinburgh Hospital \\ Morningside Park \\ Edinburgh EH $105 H F$}

\section{d-Fenfluramine and cognitive therapy in bulimia} nervosa

SIR: We feel perplexed by the design and conclusion of the study of Fahy et al (Journal, May 1993, 162, 597-603) on the concomitant use of cognitivebehavioural therapy (CBT) and d-fenfluramine in bulimia nervosa (BN). d-Fenfluramine is a fluorinated amphetamine and a potent inhibitor of 5-HT uptake. It has been shown, albeit not consistently, to reduce binge-frequency and self-induced vomiting 
among bulimic patients. The main rationale for the study design is that BN generally requires "the expense of intensive psychotherapeutic approaches to treatment", and therefore "a safe and effective treatment which could be combined with less intensive and time-consuming psychological interventions would be an important clinical advance" (p. 597). This statement is not true because the great majority of bulimics respond to an initial course (four weeks) of brief CBT (Fairburn \& Cooper, 1989), which may also be provided more cheaply in groups. Despite psychiatrists' current romance with biology and time-saving pharmacotherapy, it is hasty to label CBT as intensive and pricey therapy, especially when long-term benefits are considered (Agras et al, 1992).

The grounds for testing a drug of uncertain efficacy against placebo in patients concurrently receiving a course of CBT which contains all the essential ingredients (p. 598) of this usually brief form of firmly established psychological treatment for $\mathrm{BN}$ are debatable. This design is analogous to comparing a dubious antidepressant with placebo among endogenous depressive patients who are simultaneously undergoing an entire course of electroconvulsive therapy. The positive effect of d-fenfluramine is likely to have been deluged in that of the CBT.

As the beneficial effects of CBT tend to be maintained at follow-up, the lack of a rebound effect on discontinuation of $\mathrm{d}$-fenfluramine is expected. A more clinically relevant design would be to compare d-fenfluramine with placebo alone, a study feasible at any out-patient setting. If a favourable effect of the drug is shown, as in the case of fluoxetine in a recent large-scale $(n=387)$, eight-week, placebo-controlled, double-blind trial (Fluoxetine BN Collaborative Study Group, 1992), the next logical step will be to find out the magnitude of its long-term effect, if any, in $\mathrm{BN}$, which is known to fluctuate and recur. Alternatively, it is useful to examine whether dfenfluramine helps bulimics who have failed to respond to one or more courses of CBT, as this is a problem that disconcerts clinicians. It is at this stage, when intensive psychotherapy may be deemed obligatory, that the suggestion of Fahy et al that "dfenfluramine may have an important clinical benefit by promoting rapid symptom reduction and reducing the need for intensive psychotherapy" (p. 598) may have the opportunity of being verified.

CBT for the treatment of BN involves the repetitious and untiring impinging on patients of a cognitive-behavioural explanatory model for the vicious interactions among morbid attitudes, behaviour, and mood changes. This psychobehavioural scenario stresses active participation, self-control, and environmental restructuring. From the patients' experiential perspective, this may not accommodate the notion of 'biological' therapy in the form of a passively taken appetite suppressant. d-Fenfluramine also causes sedation and dizziness as side-effects. Another possible contribution to the frequently negative effect of d-fenfluramine or fluoxetine in bulimics receiving concurrent CBT may, speculatively, be the patients' endorsement of psychogenesis and psychotherapy, which may create clandestine non-compliance and a sort of 'nocebo' effect.

Finally, as the body mass index of patients in the study was well within the non-obese range (mean $22.5 \mathrm{~kg} / \mathrm{m}^{2}$; normal $20-25 \mathrm{~kg} / \mathrm{m}^{2}$ ), it remains to be shown whether $d$-fenfluramine is also ineffective in the sizeable population of obese bulimics. The drug has been shown to selectively suppress overeating, excessive snacking, and carbohydrate consumption among obese subjects (Wurtman et al, 1985). The perceptible weight reduction (which may require a higher dosage than $45 \mathrm{mg} /$ day, used by Fahy et al) may enhance self-image, and reduce the dysfunctional attitudes and attributional errors which perpetuate $\mathrm{BN}$. This may become especially pertinent in subjects with the newly constructed entity of 'binge eating disorder', where morbid overeating and distress in the absence of compensatory behaviour and often severe obesity occur (Spitzer et al, 1993).

Thus, even if the conclusion of Fahy et al that d-fenfluramine is not an effective treatment for $\mathrm{BN}$ is true, this does not appear to be effectively borne out by their study.

Agras, W. S., Rossiter, E. M., Arnow, B., et al (1992) Pharmacologic and cognitive-behavioural treatment for bulimia nervosa: a controlled comparison. American Journal of Psychiatry, 149, 82-87.

Fairburn, C. \& CoOper, P. (1989) Eating disorders. In Cognitive Behaviour Therapy for Psychiatric Problems (eds K. Hawton, P. M. Salkovskis, J. Kirk \& M. C. Clark), pp. 277-314. New York: Oxford University Press.

Fluoxetine Bulimia Nervosa Collaborative Study Group (1992) Fluoxetine in the treatment of bulimia nervosa. A multicenter, placebo-controlled, double-blind trial. Archives of General Psychiatry, 49, 139-147.

SPITZER, R. L., StunKard, A., YANOvSKı, S., et al (1993) Binge eating disorder should be included in DSM-IV: a reply to Fairburn et al's "The Classification of recurrent Overheating: The Binge Eating Disorder Proposal". International Journal of Eating Disorders, 13, 161-169.

Wurtman, J. J., Wurtman R. J. \& Marks, S. (1985) d-Fenfluramine selectively suppresses carbohydrate snacking by obese subjects. International Journal of Eating Disorders, 4, 89-99.

$11 / F$, Prince of Wales' Hospital

SING LeE

Shatin, Hong Kong 